\title{
Frequency of B cells in normal mice which recognize self proteins
}

M.C. Carlan, A. Peres and N.B. Nardi
Departamento de Genética, Universidade Federal do Rio Grande do Sul, 91501-900 Porto Alegre, RS, Brasil
Correspondence

N.B. Nardi

Departamento de Genética, UFRGS

Caixa Postal 15053

91501-970 Porto Alegre, RS

Brasil

Fax: 55 (051) 316-2011

E-mail: nardi@vortex.ufrgs.br

Research supported by CNPq (No. 520936/95-7).

Received April 25, 1996 Accepted December 4, 1996

\begin{abstract}
The mechanism whereby the immune system avoids self-aggression is one of the central issues of Immunology. The discovery of natural autoantibodies, mainly of IgM isotype, and of idiotypic interactions between antibodies indicates that elements of the immune system interact with self constituents and with themselves. Results of studies with soluble antibodies have indicated that the pool of circulating $\operatorname{IgM}$ represents the end result of a highly selective process of $\mathrm{B}$ cell activation and differentiation by self proteins resulting in the formation of a network. The objective of the present work was to determine the frequency of self-reacting B cells in normal mice. We were able to detect $\mathrm{B}$ cells that recognize self proteins present in extracts of different organs in normal adult, 2-3-month old, BALB/c and C57BL/ 6 mice with an ELISA spot assay. About $1 \%$ of total IgM-secreting cells among small, LPS-stimulated spleen cells reacted with organ extracts, whereas among large spleen cells the frequency was 5- to 10fold lower. Immunization induced an increase in the frequency of IgM-secreting cells. The present results provide cellular evidence for the results of studies done at the serological level. The physiological role of these self-recognizing cells, as well as their participation in autoimmune processes, remain to be established.
\end{abstract}

\section{Introduction}

The normal immune system is capable of self-recognition without triggering processes that characterize the immune response against conventional antigens. The mechanism(s) whereby the immune system avoids selfaggression is one of the central issues in Immunology.

The B cell repertoire is generated by random rearrangements of immunoglobulin genes in the absence of nominal antigens.
Key words

- B cells

- Self-recognition

- Ig repertoire

- BALB/c mice

- C57BL/6 mice

- LPS-stimulated spleen cells 
nectivity with each other and with other self components (5-7). Idiotypic connectivity and self-recognition, in agreement with the ideas of Jerne (8), lead to the formation of a network, where the elements are in equilibrium and therefore are not activated to react with self.

Recent studies with soluble antibodies have indicated that the pool of circulating IgM in normal mice represents the end result of a highly selective process; naturally activated, immunocompetent lymphocytes do not constitute a random sample of the resting cell pool, but are rather the result of a positive selection guided by self proteins and resulting in the formation of a network $(9,10)$. These studies have provided remarkable evidence for the fundamental role of self components in the establishment and maintenance of the system. Thus, a pool of lymphocytes would be selected by dominant self proteins which constitute the "immunological homunculus" as proposed by Cohen (11).

As a complementation of these studies, done at the level of soluble antibodies, the objective of the present investigation was to analyze self-reacting B cell frequencies in normal mice. Using an ELISA spot assay we were able to detect $B$ cells that recognize self proteins present in extracts of different organs in normal adult BALB/c and C57BL/6 mice. Our results show a relatively high frequency of IgM-secreting B cells that recognize self proteins, supporting reports of the existence of a positive selection mechanism on the initial development of B cells and a negative selection of mature B lymphocytes.

\section{Material and Methods}

Animals

$\mathrm{BALB} / \mathrm{c}$ and $\mathrm{C} 57 \mathrm{BL} / 6$ inbred mice were maintained under standard conditions in our animal facilities. Adult animals, 2-3 months of age, were used in these studies.

\section{Protein extracts and immunizations}

Protein extracts were prepared from the following organs: heart, lung, brain, liver, gut, spleen, kidney and stomach. Mice were killed by cervical dislocation, and the organs were removed under sterile conditions and disrupted by ultrasound ( 7 pulses of $20 \mathrm{~mA}$ for $30 \mathrm{~s}$ ) on ice-cold phosphate-buffered saline (PBS) with $35 \mu \mathrm{g} / \mathrm{ml}$ phenylmethylsulfonyl fluoride. After centrifugation at $1,000 \mathrm{~g}$ at $4^{\circ} \mathrm{C}$, the supernatant was collected and protein concentration was determined by absorbance at 260 and $280 \mathrm{~nm}$. The material was aliquoted and stored at $-20^{\circ} \mathrm{C}$ until use.

Groups of 3-4 mice were immunized on days 0 and 7 by intraperitoneal injection of $50 \mu \mathrm{g}$ lung protein extract diluted in $100 \mu \mathrm{l}$ PBS and emulsified in the same volume of complete Freund's adjuvant (CFA, Sigma Chemical Co.). Control groups consisted of animals injected with $100 \mu \mathrm{l}$ PBS or PBS/ CFA. On day 10 spleen cells were screened for the frequency of Ig-secreting cells recognizing the organ extracts by the ELISA spot assay (ESA).

\section{Cells and cultures}

Cells from spleen, peritoneal exudate and bone marrow were collected from mice under sterile conditions, washed with cold Hank's solution, adjusted to the desired concentration and kept in an ice bath until use. Large and small spleen cells were separated by centrifugation using a Percoll gradient (12).

For some experiments, cells were suspended at $10^{6}$ or $2 \times 10^{6} / \mathrm{ml}$ in RPMI 1640 medium (Sigma Chemical Co.) complemented with $25 \mathrm{mM}$ HEPES buffer (Sigma), pH 7.3, gentamycin $(280 \mathrm{mg} / \mathrm{l}), 10 \%$ fetal calf serum (Cultilab, São Paulo, Brazil) and $25 \mu \mathrm{g} / \mathrm{ml} \mathrm{E}$. coli lipopolysaccharide (LPS, Sigma) and cultured for 3 days at $37^{\circ} \mathrm{C}$ with $5 \% \mathrm{CO}_{2}$ in air. After this period, they were 
washed, counted and analyzed for the frequency of Ig-secreting cells by ESA.

\section{ELISA spot assay}

The ELISA spot assay was performed as described by Nardi et al. (12). Briefly, flatbottom ELISA plates were coated with 50 $\mu \mathrm{l} /$ well of either anti-mouse Ig (Sigma Chemical Co.) or protein extracts at $1 \mathrm{mg} / \mathrm{ml}$. After saturating the plates with PBS containing $1 \%$ non-fat milk and washing with PBS, cells were added in serial dilutions starting with the appropriate concentrations (usually, $10^{3}$ to $10^{6}$ cells in $100 \mu \mathrm{l}$ ). Plates were incubated at $37^{\circ} \mathrm{C}$ for $3 \mathrm{~h}$ and the cells were then lysed by washing with distilled water. Rabbit anti-mouse IgG, IgM or IgA coupled to biotin (Sigma) was added and after standing overnight at $4^{\circ} \mathrm{C}$ the plates were incubated for $1 \mathrm{~h}$ at $37^{\circ} \mathrm{C}$ with a solution of streptavidin coupled to alkaline phosphatase (Sigma). The substrate consisted of a solution of 2.3 mM 5-bromo-4-chloro-3-indolylphosphate (Sigma) diluted in 2-amino-2methyl-1-propanol buffer (Merck) containing $0.75 \%$ low-melting agarose (type 1 , low EEO; Sigma). After a 3-4-h incubation period at $37^{\circ} \mathrm{C}$, the Ig-secreting cells, visualized as blue spots, were counted, and their frequency was determined in relation to the total number of cells added to the well.

\section{SDS-PAGE}

Protein electrophoresis was performed by SDS-PAGE in the presence of mercaptoethanol with a $4 \%$ stacking gel and 10\% separating acrylamide gel.

\section{Results}

As expected, complex protein patterns were observed after SDS-PAGE of the extracts (data not shown), and protein integrity was periodically monitored with this assay.

The ESA was highly reproducible, as

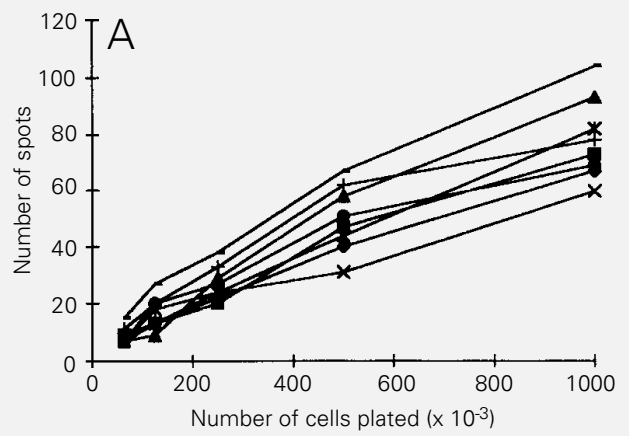

Figure 1 - Frequency of BALB/C total spleen cells secreting antiself IgM antibodies without (A) or with (B) LPS stimulation. Note that the ordinate of panel $A$ refers to thousands of cells plated and panel $B$ refers to hundreds of cells plated. $\bullet$, Kidney; $\mathbf{\Lambda}$, stomach; $\boldsymbol{\square}$, gut; $\times$, heart; $\boldsymbol{*}$, spleen; +, liver; $\bullet$, lung: -, brain.

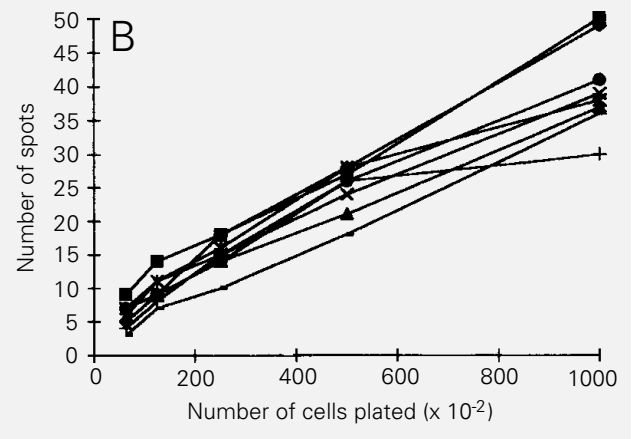

indicated by the same results after 5 to 8 repetitions. The results reported here were obtained in at least three different experiments. Initially, the frequency of BALB/c cells secreting anti-self antibodies was determined in total spleen with or without LPS stimulation. Figure 1 shows that the frequency of antibody-secreting cells recognizing protein extracts is closely similar for all organs, and in LPS-stimulated spleen is about 5- to 10-fold higher than that of non-stimulated spleen cells. Only the IgM isotype was detected. Assays in which the plates were covered with irrelevant foreign proteins such as bovine serum albumin or casein showed that $10 \%$ of the cells were of the "sticky" type (data not shown).

Since extracts from all 8 organs presented the same results when assayed by ESA, 3 of them (gut, brain and lung) were selected for further study. Total IgM-secreting cells in this assay were detected at frequencies of $2.5 \%$ and $11.0 \%$ among large and LPS-stimulated small spleen cells, respectively. Analysis of these cells in BALB/c mice showed very different frequencies of self-reacting $B$ 
Figure 2 - Frequency of cells secreting IgM antibodies reactive with self components among IgM-secreting large (A) and LPSstimulated small (B) spleen cells of $B A L B / c$ mice. Note that the ordinate scales of both panels $A$ and $B$ refer to thousands of cells plated. $\bullet$ Gut; $\mathbf{\Lambda}$, brain; $\mathbf{\square}$ lung. cells. As shown in Figure 2, almost 10 times more cells secreting antibodies recognizing self components were found among IgMsecreting small spleen cells than among large spleen cells.
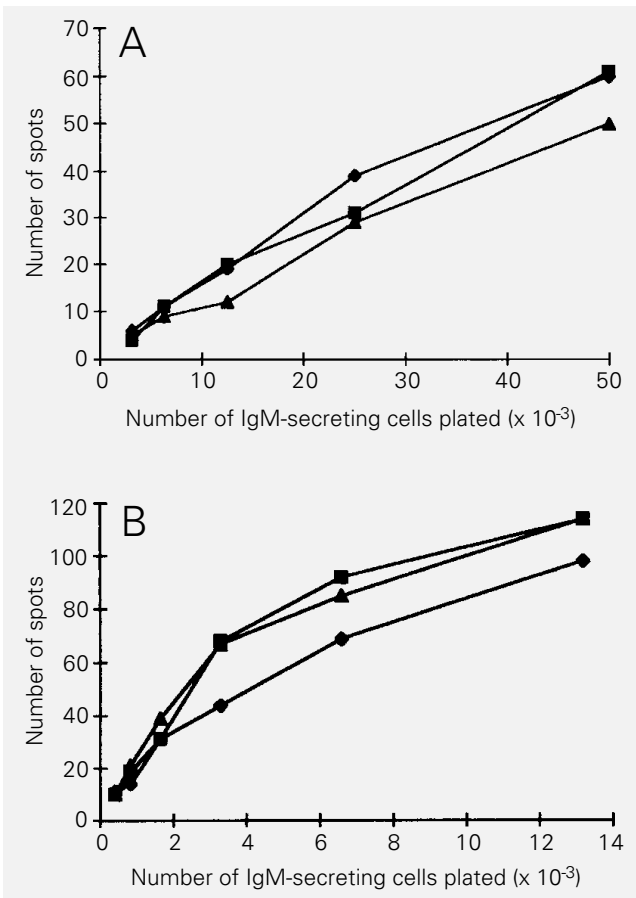

Figure 3 - Frequency of cells secreting IgM antibodies reactive with self components among IgM-secreting spleen cells obtained from mice immunized with lung extract plus CFA (A) or CFA alone (B). $\bullet$ Gut; $\mathbf{\square}$, lung.
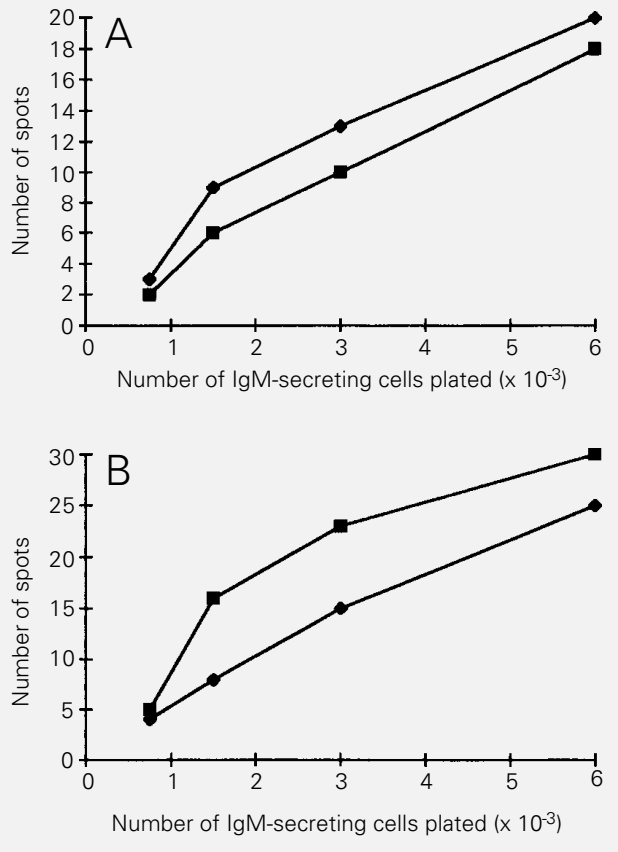

The spleen of immunized mice presented a 3-fold increase in the frequency of IgMsecreting $\mathrm{B}$ cells recognizing lung and intestine extract; the results were the same whether the animals received the protein extract in CFA or CFA alone (Figure 3).

Frequencies of antibody-secreting cells reactive with gut, brain and lung extracts were analyzed in C57BL/6 mice, and did not differ from those found for BALB/c mice (data not shown).

\section{Discussion}

Evidence has been accumulating which supports the hypothesis that differentiation in the immune system is driven by self as well as foreign antigens, and that this antiself reactivity is under control to prevent autoimmunity (13). Whereas at the $\mathrm{T}$ cell level the presence of anti-self cells has been demonstrated in several studies $(14,15)$, the B lymphocyte compartment has been studied mainly at the antibody level. The pool of normal serum antibodies, as well as monoclonal antibody collections prepared from normal mice, present extensive autoreactivity $(16,17)$.

The objective of the present study was to characterize the $\mathrm{B}$ cell compartment at the cellular level, and the frequency of B lymphocytes reacting with self components was determined by ESA in normal BALB/c and C57BL/6 mice. In order to obtain a broader analysis of the reactivity repertoire, protein extracts from organs, instead of purified antigens were used in the assay. This approach imposes a limitation in terms of being able to identify the proteins towards which reactivity is directed, and the results obtained must be interpreted in terms of experiments carried out with soluble antibodies of known specificity. Thus, the results obtained in the present study represent the cellular counterpart of studies done at the humoral level.

Closely similar levels of reactivity were found for all eight organ extracts employed 
in this study. The possibility that this reactivity could be due only to multispecific, "sticky" B cells which are present in normal individuals (13) was eliminated by experiments which showed that about $10 \%$ of the B cells detected in the assay reacted with unrelated proteins. Actually, analysis of natural antibodies has shown that even polyreactive antibodies discriminate between the antigens they recognize (18), and that they present fine specificity towards a) defined subsets of antigens present in different organ extracts as well as b) different antigens within various strains (9). These results suggest that the basal frequencies of anti-self B cells detected in the present study, if analyzed for their fine specificities, should present discriminated profiles for different organ extracts.

About $1 \%$ of total IgM-secreting cells among small, LPS-stimulated spleen cells reacted with organ extracts; among large spleen cells, this frequency was 5-10-fold lower. The fact that the frequency of selfrecognizing $B$ cells is higher among cells in the available repertoire than in the actual repertoire, though disagreeing with some reports (19), is in agreement with several others $(9,20,21)$, and represents the result of selection of the $B$ cell repertoire by self antigens (13). An alternative explanation for the lower frequency of positive cells scored among naturally activated B cells is that multireactivity has been shown to decrease with the maturation stage of the B cell population analyzed (21).

As expected, immunization induced an increase in the frequency of IgM-secreting B cells; the effect is probably of a polyclonal, multispecific nature, and induced by mycobacterial antigens, since the same results were observed when mice were immunized with organ extracts and CFA or CFA alone.

Some other studies have been conducted to investigate the frequency of anti-self $B$ lymphocytes. Thus, selection of self-reacting $B$ cells by proteins such as the $F$ antigen (12) or heat shock proteins (22) has been reported in mice. This approach, however, is restricted to a few antigens. The study reported here, although not permitting the identification of antigens towards which B lymphocytes are directed, provides cellular evidence for the results obtained at the serological level. The physiological role of these self-recognizing cells, as well as their participation in autoimmune processes (23), remain to be established.

\section{References}

1. Hooijkaas H, Benner R, Pleasants JR \& Wostmann BS (1984). Isotypes and specificities of immunoglobulins produced by germ-free mice fed chemically defined ultrafiltered "antigen-free" diet. European Journal of Immunology, 14: 1127-1130.

2. Pereira $P$, Forni L, Larsson EL, Cooper MD, Heusser C \& Coutinho A (1986). Autonomous activation of $\mathrm{T}$ and $\mathrm{B}$ cells in antigen-free mice. European Journal of Immunology, 16: 685-688.

3. Lundkvist I, Coutinho A, Varela F \& Holmberg D (1989). Evidence for a functional idiotypic network among natural antibodies in normal mice. Proceedings of the National Academy of Sciences, USA, 86: 5074-5078.
4. Varela FJ, Anderson A, Dietrich G, Sundblad A, Holmberg BD, Kazatchkine M \& Coutinho A (1991). Population dynamics of natural antibodies in normal and autoimmune individuals. Proceedings of the National Academy of Sciences, USA, 88: 5917-5921

5. Coutinho A (1989). Beyond clonal selection and network. Immunological Reviews, 110: 63-87.

6. Varela FJ \& Coutinho A (1991). Second generation immune networks. Immunology Today, 12: 159-166.

7. Coutinho A, Freitas AA, Holmberg D \& Grandien A (1992). Expression and selection of murine antibody repertoires. International Review of Immunology, 8: 173187.
8. Jerne NK (1974). Towards a network theory of the immune system. Annales de I'Institute Pasteur, Immunologie, 125C: 373-389.

9. Nobrega A, Haury M, Grandien A, Malanchère $E$, Sundblad A \& Coutinho A (1993). Global analysis of antibody repertoires. II. Evidence for specificity, self-selection and the immunological "homunculus" of antibodies in normal serum. European Journal of Immunology, 23: 28512859

10. Haury M, Grandien A, Sundblad A, Coutinho A \& Nobrega A (1994). Global analysis of antibody repertoires. I. An immunoblot method for the quantitative screening of a large number of reactivities. Scandinavian Journal of Immunology, 39: 79-87. 
11. Cohen IR \& Young DB (1991). Autoimmunity, microbial immunity and the immunological homunculus. Immunology Today, 12: 105-110.

12. Nardi NB, Freitas A \& Coutinho A (1990). Selection of anti-F protein B-cell repertoires in normal mice. Research in Immunology, 141: 711-721.

13. Avrameas S (1991). Natural autoantibodies: from "horror autotoxicus" to "gnothi seauton". Immunology Today, 12: 154159.

14. Schild H, Rotzschke O, Kalbacher $H$ \& Rammensee HG (1990). Limit of $T$ cell tolerance to self proteins by peptide presentation. Science, 247: 1587-1589.

15. Shoenfeld Y, Teplitzki HA, Mendlovic S, Blank M, Mozes E \& Isenberg DA (1989). The role of the human anti-DNA idiotype 16/6 in autoimmunity. Clinical Immunology and Immunopathology, 51: 313-325.

16. Dighiero G, Guilbert B \& Avrameas $S$ (1982). Naturally occurring antibodies against nine common antigens in human sera. High incidence of monoclonal lg exhibiting antibody activity against actin and tubulin and sharing antibody specificities with natural antibodies. Journal of Immunology, 128: 2788-2792.
17. Holmberg D, Freitas A, Portnoi D, Jacquemart F, Avrameas S \& Coutinho A (1986). Antibody repertoires of normal BALB/c mice: B lymphocyte populations defined by state of activation. Immunological Reviews, 93: 147-169.

18. McHeyzer-Williams MG \& Nossal GVJ (1988). Clonal analysis of autoantibodyproducing cell precursors in preimmune B cell repertoire. Journal of Immunology, 141: 4118-4123.

19. Portnoi D, Freitas A, Bandeira A, Holmberg D \& Coutinho A (1986). Immunocompetent autoreactive B lymphocytes are activated cycling cells in normal mice. Journal of Experimental Medicine, 164: 25-35.

20. Ishigatsubo $Y$, Steinberg AD \& Klinman DM (1988). Autoantibody production associated with polyclonal B cell activation in autoimmune mice which express the Ipr or gdl genes. European Journal of Immunology, 18: 1089-1093.
21. Grandien A, Fucs R, Nobrega A, Andersson J \& Coutinho A (1994). Negative selection of multireactive $B$ cell clones in normal mice. European Journal of Immunology, 24: 1345-1352.

22. Bonorino $C$, Folberg A, Silveira R \& Nardi $N$ (1993). Heat shock proteins and the shaping of the B cell compartment. Anais do III Congreso de la Associacion Latinoamericana de Inmunologia: 171A.

23. Bockenstedt LK, Gee RJ \& Mamula MJ (1995). Self-peptides in the initiation of lupus autoimmunity. Journal of Immunology, 154: 3516-3524. 